\title{
Hábitos Alimentares e Concepções sobre Alimentação Equilibrada: Uma Investigação com Alunos do Oitavo Ano do Ensino Fundamental
}

\section{Food Habits and Concepts of Balanced Nutrition: An Investigation with $8^{\text {th }}$ Graders of in an Elementary School}

\section{Camila Maria Bandeira Scheunemann ${ }^{\text {; }}$ Paulo Tadeu Campos Lopes ${ }^{\mathrm{a}}$}

a Universidade Luterana do Brasil, Canoas, Brasil - camila.b91@ hotmail.com, pclopes@ulbra.br

Palavras-chave: Alimentação equilibrada. Concepções. Ensino de ciências. Hábitos alimentares.
Resumo: Esta pesquisa teve por objetivo investigar as concepções de estudantes do Ensino Fundamental sobre seus hábitos alimentares e alimentação equilibrada. Este estudo qualitativo e caracterizado como pesquisa exploratória incluiu 15 alunos do oitavo ano do Ensino Fundamental de uma escola estadual da região noroeste do estado do Rio Grande do Sul, Brasil. Os dados foram coletados mediante questionário e discutidos com base em uma análise de conteúdo. Os resultados revelaram que os alunos compreendem ao menos em parte a importância de uma alimentação balanceada para a saúde. Além disso, os participantes contribuíram com concepções variadas sobre alimentação balanceada, algumas das quais apresentaram uma relação com os conhecimentos científicos associados, ao passo que outras eram embasadas principalmente em conceitos espontâneos. Contudo, algumas concepções sobre o tema careceram de robustez, o que aponta para a necessidade de aprofundar a discussão sobre alimentação equilibrada na escola.
Keywords:

Balanced nutrition.

Concepts. Teaching of sciences. Food habits.
Abstract: The objective of this study was to investigate the concepts Elementary School students have of food habits and balanced nutrition. This qualitative exploratory study included $158^{\text {th }}$ grade students of an elementary school in northwestern Rio Grande do Sul state, Brazil. Data were collected using a questionnaire and assessed based on the content analysis approach. The results showed that students have a certain degree of knowledge about the importance of a varied diet to health. In addition, they expressed several concepts of balanced nutrition, some of which were spontaneous in character, while others revealed a narrower relationship with associated scientific knowledge. Despite that, some concepts lacked consistency concerning the topic, indicating the need for further indepth discussions about it. 


\section{Introdução}

O ensino de Ciências contempla diversos aspectos relacionados à saúde, como as questões referentes à alimentação humana, por exemplo. Nesse tema destacam-se o estudo e as discussões sobre hábitos alimentares dos estudantes e suas concepções sobre alimentação.

Logo, cabe primeiramente discutir o termo hábito alimentar, o qual tem sido amplamente utilizado como sinônimo de comportamento alimentar. No entanto, uma discussão elucidativa sobre alimentação balanceada não pode prescindir da clara diferenciação dos termos dados. Klotz-Silva et al. (2016, p. 1106) empenharam-se na reflexão sobre as semelhanças e as diferenças entre os dois termos. Para os autores, "hábitos e comportamentos alimentares podem ser analisados de formas iguais ou diferentes, com intenções e propósitos diversos". Além disso, enquanto "os hábitos são relacionados à ideia de consumo alimentar [...], o comportamento alimentar aparece, na maioria das vezes, relacionado aos aspectos psicológicos da ingestão da comida" (KLOTZ-SILVA et al., 2016, p. 1107).

O comportamento alimentar é influenciado pela interação entre aspectos ambientais, psicológicos e biológicos. Essa interação caracteriza as atitudes perante o alimento, e o comportamento alimentar apresenta-se como um dos fatores do estilo de vida que influencia diretamente a condição de saúde do indivíduo. Em função de suas particularidades o comportamento alimentar tem a Psicologia como disciplina investigativa mais intimamente relacionada a ele (VIANA, 2002). Para Freitas (2016), as quatro dimensões mais significativas do comportamento alimentar são a ingestão emocional, a ingestão externa, a ingestão compulsiva e a restrição alimentar.

A partir dessa diferenciação optou-se, neste artigo, por utilizar o termo hábito alimentar com base no fato de ele trazer o sentido de repetição de determinada ação. Tal repetição é um elemento de importância considerável para pensar a prática alimentar do público participante desta pesquisa.

As orientações teóricas referentes a temas intimamente associados à saúde, como a alimentação, por exemplo, têm forte vínculo com o ensino de Ciências. Contudo, as pesquisas sobre o tema sublinham a necessidade de contemplar práticas interdisciplinares e transversais no âmbito escolar (SILVA et al., 2015b).

De modo geral os hábitos alimentares da população, mas especialmente os de crianças e adolescentes, são tidos como inadequados (SODRÉ; MATTOS, 2013). É o que indica o elevado consumo de alimentos prontos e industrializados. Isso se deve, em parte, ao ritmo acelerado do cotidiano contemporâneo, marcado pelo crescente consumo de lanches rápidos em detrimento do preparo de refeições saudáveis no momento do consumo. 
Tanto no Brasil como em outros países, diversos fatores favorecem essa mudança em padrões alimentares, como o processo de urbanização e a atuação da mulher no mercado de trabalho, por exemplo. Esses fatores contribuem com o aumento do número de refeições realizadas fora de domicílio, em uma situação na qual as pessoas muitas vezes acabam optando por alimentos semipreparados ou lanches (SODRÉ; MATTOS, 2013).

As transformações sofridas pela humanidade ao longo do tempo, as quais culminaram com o progresso industrial e agrícola, acabaram afastando as pessoas de uma visão holística sobre alimentação, direcionando-as a abraçarem uma percepção mais prática e limitada dessa temática (ELIAS; FONSECA, 2009). Em tempos não muito distantes, o convívio familiar nos horários das refeições era tido como prática respeitável; porém, gradualmente esse costume cedeu lugar à maior praticidade, a qual se manifesta como busca por refeições rápidas (CARDOSO; BELO, 2015).

No entanto, sabe-se que esse tipo de alimentação caracterizada por refeições prontas e rápidas pode favorecer o surgimento de diversos transtornos de saúde, fator este que coloca a temática alimentação em destaque no ensino de Ciências. Por essa razão, torna-se imprescindível a conscientização dos estudantes sobre a importância de uma alimentação equilibrada.

Essa mudança de hábito alimentar atinge de forma especial os adolescentes, que costumam substituir refeições completas por lanches ou até deixar de realizar determinada refeição em horário convencionado para voltar a consumir alimentos horas mais tarde, quando a refeição seguinte seria esperada. Gasior et al. (2016) analisaram a frequência de consumo e o salto entre refeições praticados por jovens. Os autores constataram que ingerir três refeições diárias como o café da manhã, o almoço e o jantar são hábitos observados por apenas alguns dos entrevistados.

Além disso, independentemente de uma refeição ser preparada em domicílio, a questão relacionada à escolha pessoal tem peso notável na qualidade de vida. De modo geral os jovens preferem o consumo de alimentos de alto teor energético, preferência esta que aumenta de acordo com a renda familiar. Além disso, em grande parte das vezes esses adolescentes deixam de lado o consumo de frutas e verduras, os quais são alimentos essenciais para a manutenção da saúde (SICHIERI, 2013).

A discussão sobre essas escolhas e hábitos mostra a importância de entender que a alimentação "não deve ser entendida somente como uma consequência de fenômenos biológicos ou ecológicos. Ela também é um dos principais fatores estruturantes da organização social” (GIORGI, 2015, p. 737). Portanto, embora os hábitos alimentares tenham relação com aspectos biológicos, as questões sociais também precisam ser consideradas no que se refere à constituição desses hábitos. 
O estudo de hábitos alimentares, assim como o da composição de alimentos e seus nutrientes, deve ser ponto de consenso na definição de alimentação saudável. É mediante o processo educativo que os estudantes conseguem adquirir e aperfeiçoar os meios de realizar suas escolhas (BORGES et al., 2015). Logo, a promoção de tal abordagem educativa possibilita aos alunos refletir e, com base nessa reflexão, adotar uma postura alimentar que privilegie a saúde, mais adequada às necessidades nutricionais do organismo.

Esse discernimento proporcionado aos estudantes faz com que aprendam a realizar suas escolhas alimentares de forma consciente, as quais serão decisivas para sua saúde. A abordagem de aspectos relativos à saúde permite ao educando ampliar os seus conhecimentos sobre o entendimento nutricional, provendo-lhe a capacidade de optar por atitudes sadias e benéficas (MOLIN; SOARES, 2016).

Assim como a família, a escola pode também influenciar a adoção de bons hábitos e, em um movimento interessante, a escola pode se tornar elemento de influência nos hábitos alimentares de toda uma família, tendo o aluno como intermediário (CARDOSO; BELO, 2015). Além disso, os benefícios desses hábitos podem acompanhar o aluno em toda a sua trajetória de vida. A escola se apresenta como ambiente propício para a prática da educação alimentar e nutricional, já que representa o segundo grupo social em importância na formação do indivíduo, precedido pela família (ROCHA; FACINA, 2017).

A partir dos fatores mencionados, o estudo dos hábitos alimentares dos estudantes e suas concepções sobre alimentação equilibrada tornam-se fundamentais. A partir do conhecimento dos hábitos alimentares de seus alunos, os docentes podem encontrar subsídios para proceder de forma mais assertiva nas estratégias pedagógicas a serem desenvolvidas.

De posse de tais informações o professor tem melhores condições de direcionar suas atividades, empreendendo esforços para contribuir na aprendizagem sobre bons hábitos. As concepções que os alunos trazem de suas vivências são chamadas de prévias, ou alternativas, e já tiveram sua importância demonstrada no ensino e na aprendizagem, pois facilitam e promovem tais processos (RIGUI et al., 2011).

Os saberes que os alunos trazem de suas vivências são ferramentas úteis em potencial na aprendizagem de Ciências, auxiliando na construção de sentidos e na aproximação entre tais saberes e os científicos (LOBO et al., 2013).

Considerando essas reflexões, este estudo examinou os hábitos alimentares de estudantes de uma turma de oitavo ano do Ensino Fundamental, avaliando as concepções destes sobre alimentação equilibrada. A partir desse contexto, esta pesquisa teve por objetivo investigar as concepções de uma turma de estudantes do oitavo ano do Ensino Fundamental sobre seus hábitos alimentares e alimentação equilibrada. 


\title{
Os hábitos alimentares e o Ensino de Ciências
}

Os adolescentes em idade escolar têm desenvolvido hábitos alimentares pouco saudáveis, o que aumenta a probabilidade de serem afetados por problemas de saúde futuros. As escolhas alimentares inadequadas têm sido relacionadas ao aumento de doenças como a “obesidade, diabetes, hipertensão, alergias [...]" (ZOMPERO et al., 2015, p. 72). Diante desse fato, é preciso priorizar a adoção de estratégias para estabilizar ou diminuir a prevalência dessas doenças entre os jovens. Tais estratégias devem incluir procedimentos referentes a mudanças nos hábitos alimentares e a prática de atividades físicas, além do tratamento de barreiras psicológicas e comportamentais (FAN; JIN, 2015).

É nesse cenário que a escola se apresenta como um espaço importante de abordagem dessa temática, dada a necessidade de construir hábitos alimentares saudáveis, considerando que

\begin{abstract}
O tema alimentação representa uma demanda social por conhecimento e troca de informações acerca de cuidado com a saúde dentro e fora da escola, constituindo-se enquanto um fenômeno multifacetado que engloba questões culturais, biológicas e sociais, entre outras (LOBO; MARTINS, 2013, p. 2).
\end{abstract}

Nesse sentido, a investigação dos hábitos alimentares de adolescentes ganha destaque crescente nos currículos, em decorrência do aumento dos problemas de saúde apresentados por essa população (BIZZIO et al., 2009).

Apesar de sua relevância, o tópico alimentação e nutrição por vezes é abordado superficialmente, em função da necessidade de os docentes cumprirem todos os conteúdos estipulados pelo currículo. Por essa razão, em muitos casos são tratados apenas alguns aspectos, como a composição dos alimentos e a fisiologia da digestão, por exemplo (TAMAYO et al., 2015).

Para um aluno, o ensino de Ciências atua como suporte para o entendimento da importância de uma alimentação adequada. Contudo, esse papel deve ser trabalhado com criticidade, para que esse aluno possa aprender a tomar suas decisões alimentares pensando na promoção de sua saúde. Essa abordagem gera a conscientização, não a imposição. Para tal, é importante que esse processo seja realizado de forma progressiva e perseverante em todos os meios de convívio do aluno (RODRIGUES et al., 2011).

Além da necessidade de a educação alimentar e nutricional ser adequada em função do desenvolvimento físico dos alunos, há também que se considerar que é nessa etapa da vida que os estudantes estão em fase de formação de conceitos e valores (GREENWOOD; FONSECA, 2016); nesse contexto, "o ensino da saúde é apropriado para trabalhar com cuidado a dimensão das atitudes e valores" (BRASIL, 1998, p. 46).

Portanto, seja na infância, seja na adolescência, essa orientação apresenta-se como indispensável, já que se trata de uma etapa decisiva capaz de influenciar a formação dos 
hábitos que acompanharão esse aluno no decorrer de sua vida. "Verifica-se que a alimentação saudável se aprende na escola, e que na infância é o período ideal para a construção da percepção dos hábitos alimentares e da alimentação saudável [...]”" (BORGES et al., 2015, p. 99).

Os hábitos adquiridos na infância criam raízes profundas, e o sujeito dificilmente os abandona ao chegar à vida adulta; apesar disso, até os adolescentes que apresentam peso ideal para sua faixa etária precisam receber uma educação nutricional adequada (GASIOR et al., 2016). Dito de outro modo, o tema nutrição saudável é indispensável para as crianças, uma vez que as chances de se tornarem adultos saudáveis aumentam se estudarem o tema já no começo do processo educativo (ERCAN, 2014).

No tocante a hábitos alimentares dos estudantes, deve-se ter em mente também o fator social, o qual pode contribuir para o entendimento das escolhas feitas por essa população. A alimentação é uma dimensão social importante, visto que as percepções sobre ela possibilitam compreender a influência dos gostos, convicções e valores de grupo, os quais se apresentam como um ideal ao mesmo tempo coletivo e simbólico. Manifestando-se como regras compartilhadas em determinado grupo, esse ideal pode variar de uma cultura para outra, o que lhe confere identidade cultural (GIORGI, 2015).

A escola precisa estar consciente de seu papel educativo sobre os temas alimentação e nutrição, já que integram o currículo. A construção de hábitos, mesmo sendo influenciada pela escola e pela família, necessita também de um esforço pessoal, através das escolhas e opções diárias de alimentação (CARVALHO; MACHADO, 2014).

A autopercepção sobre o próprio peso é também um fator que influencia o êxito das estratégias de alimentação adequada. Nesse sentido, essa forma de percepção sobre o peso, quando correta, pode auxiliar na mudança de postura acerca dos hábitos alimentares do indivíduo e na prática de atividades físicas. Sabe-se que a percepção equivocada sobre o próprio peso pode gerar distúrbios alimentares, entre outros problemas (FAN; JIN, 2015).

Nessa perspectiva, documentos oficiais como os Parâmetros Curriculares Nacionais, por exemplo, os quais estabelecem as diretrizes para o ensino de Ciências, trazem recomendações a respeito da importância das abordagens dadas a essas informações nas escolas. Esses documentos têm papel orientador, ao enfatizarem a discussão de questões referentes a hábitos alimentares e as transformações que sofrem devido à atuação de variáveis como a cultura, a conscientização alimentar, a valorização do cuidado com o corpo, as doenças provenientes da carência nutricional, o papel da mídia na influência dos hábitos e o consumo de produtos industrializados (BRASIL, 1998). 
Também a Base Nacional Comum Curricular aponta os hábitos alimentares como objeto de conhecimento, frisando a necessidade da adoção de cuidados com o corpo, como a alimentação equilibrada e a autonomia associada a essa prática (BRASIL, 2017).

Como outro tema contemplado em documentos oficiais a exemplo das Diretrizes Curriculares Nacionais e os Parâmetros Curriculares Nacionais, enfatiza-se a necessidade de os docentes darem a devida importância aos temas relativos à saúde. Entre esses temas está a alimentação saudável, a qual deve ser abordada a partir de uma perspectiva que considere os conhecimentos existentes dos discentes, buscando promover a autonomia e a criticidade desse grupo diante das escolhas alimentares que seus integrantes devem fazer (ZOMPERO et al., 2015).

\section{As concepções dos alunos sobre a alimentação equilibrada}

A dificuldade que cerca a compreensão conceitual relacionada a alimentos e nutrientes na Educação Básica é enfatizada na pesquisa sobre o tema. No entanto, a clareza acerca desses conceitos é fator chave na eficácia dos projetos que têm por objetivo a educação alimentar (ZOMPERO et al., 2017).

Diversos pontos merecem destaque em relação às concepções dos estudantes sobre alimentação. É preciso considerar que os alunos trazem consigo concepções prévias, adquiridas ao longo de suas vivências em contato com a família e o meio social amplo. A noção de alimentação se encontra fortemente relacionada com as práticas alimentares presentes na história familiar e os contextos social e cultural dos sujeitos (SUSANA; LONGHI, 2006). Além da influência familiar, a mídia é fonte de apelos fortes e atrativos ao consumo de alimentos que, na maioria dos exemplos, são de alto teor calórico.

Dessa forma, tais concepções são formadas a partir de diversos contextos e influências, já que "a transmissão da cultura alimentar pode ocorrer através de diferentes meios como escola, meios de comunicações e também família" (RIGUI et al., 2012, p. 3). Todas essas influências contribuem na formação de concepções que, muitas vezes, são difíceis de serem "confrontadas" pelos conhecimentos científicos, pois

O aprendizado de conceitos científicos é um processo lento e difícil, porque as concepções prévias dos estudantes diferem usualmente dos aspectos centrais das formulações científicas, ainda que as concepções prévias sejam importantes (RIGUI et al., 2011, p. 67).

Mortimer reconhece um modelo alternativo para compreender as concepções dos alunos, trazendo a noção de perfil conceitual. Assim, o autor sugere que a abordagem didática ao tema não tente substituir as concepções prévias dos estudantes; ao contrário, essas concepções existentes podem coexistir com as concepções científicas sobre o tema. O perfil conceitual torna possível compreender as ideias dos alunos como evolução de um perfil de 
concepções, não como uma substituição das concepções prévias por aquelas de origem científica. Em síntese, o autor argumenta que essa coexistência de concepções pode ser empregada em contextos distintos, isto é, de acordo com a conveniência (MORTIMER, 1996). Segundo essa compreensão, a construção do novo conhecimento não exige a substituição de conceitos prévios, mas a possibilidade dessa coexistência, propiciando a convivência de conhecimentos paralelos e prévios utilizados em contextos adequados (TEIXEIRA; SOBRAL, 2010).

É oportuno o entendimento de que os discentes passam por um processo contínuo de interação social, seja na escola, seja fora dela. Nesse processo, tanto os conhecimentos formais como os informais desempenharão um papel na formação de conceitos que terão o status de conhecimentos prévios em determinado momento futuro. Tal construção prévia, fundamentada em uma lógica diversa daquela das ciências, por hora será capaz de mitigar a curiosidade dos alunos e responder a suas inquietudes. No entanto, é preciso considerar que essas construções existentes são o ponto de partida para novas construções conceituais. Essas concepções podem se tornar o suporte para um novo patamar no esforço de superar os conceitos prévios com base na ideia de desenvolvimento conceitual (BRASIL, 1998), visão esta que difere daquela proposta por Mortimer (1996), a qual propõe a existência de um perfil conceitual.

A análise da complexidade da temática alimentar revela também a vinculação entre o conhecimento científico evidenciado em aulas de ciências e as demandas associadas às rotinas alimentares. Por essa razão, é relevante ponderar sobre os conceitos prévios dos alunos, não apenas a aprendizagem conceitual (LOBO et al., 2013).

Em decorrência da relevância do conhecimento das concepções dos alunos sobre alimentação equilibrada, diversas pesquisas se empenharam em esclarecer o peso dessa premissa. Toral et al. (2009) observaram que adolescentes que frequentam a escola apresentavam conceitos coerentes de alimentação saudável e que os pais exercem influência positiva nos hábitos alimentares de seus filhos. Já na pesquisa de Oztas e Oztas (2017) os alunos demonstraram compreender que alimentos são fonte de energia; porém, os participantes revelaram desconhecer as outras funções de um alimento, como o papel de agente de crescimento e reparação de tecidos no organismo, por exemplo.

Mello et al. (2013, p. 5) examinaram declarações dos alunos participantes sobre os conceitos relativos à alimentação adequada e revelaram que os discentes sabem diferenciar alimentos que contribuem com a saúde daqueles que a prejudicam. Contudo, os autores destacam a ideia de que os alunos entrevistados não compreendem a função dos nutrientes com a necessária clareza. 
Em sua pesquisa Cardoso e Belo (2015) discutiram o desconhecimento dos estudantes sobre a importância do consumo de frutas e verduras e de alimentos benéficos para a saúde. Rigui et al. (2011, p. 73) constataram que as concepções prévias dos estudantes sobre alimentação são resistentes às mudanças, "mesmo que novos conhecimentos sejam adquiridos e que a saúde seja uma constante preocupação dos alunos e também dos professores".

\section{Metodologia}

Esta pesquisa foi realizada segundo uma abordagem qualitativa. A expressão pesquisa qualitativa designa uma concepção vasta, a qual abrange diversas metodologias e técnicas investigativas. $\mathrm{O}$ termo refere-se a um movimento organizado que busca o entendimento de manifestações educativas e sociais, lançando luz sobre as transições de padrões existentes nesses cenários (ESTEBAN, 2010). Este estudo exploratório de abordagem qualitativa busca "proporcionar maior familiaridade com o problema, com vistas a torná-lo mais explícito ou construir hipóteses [...] e tem como objetivo principal o aprimoramento de ideias ou a descoberta de intuições" (GIL, 2002, p. 41).

Este artigo apresenta os resultados parciais de uma pesquisa de mestrado realizada no decorrer de 2016 e 2017, a qual foi aprovada pelo Comitê de Ética em Pesquisas em Seres Humanos da Universidade Luterana do Brasil, sob o número CAAE 59951516.0.0000.5349.

Os participantes foram uma turma composta por 15 estudantes do oitavo ano do ensino fundamental de uma escola estadual do município de Ajuricaba, na região noroeste do Rio Grande do Sul. Os alunos que frequentam a escola são oriundos de ambientes rurais e urbanos, e foram autorizados por seus responsáveis a participar da pesquisa após assinatura de Termo de Consentimento Livre e Esclarecido.

A amostra por saturação foi determinada em função do ano escolar e do conteúdo abordado nele. Ou seja, optou-se por escolher alunos do oitavo ano do Ensino Fundamental porque os discentes cursando essa série já tiveram contato com os conceitos referentes à alimentação e nutrição humana, isto é, a temática principal desta pesquisa. Com isso, esperava-se que o aprendizado dos conceitos científicos relacionados com o tema desta investigação já tivesse sido oportunizado aos participantes deste estudo.

Os critérios de inclusão dos participantes determinaram que os alunos elegíveis estivessem cursando o oitavo ano do Ensino Fundamental da referida escola, tivessem autorização de seus pais ou responsáveis legais e aceitassem a participação na pesquisa por meio da entrega dos termos de consentimento e assentimento. Os critérios de exclusão foram a negativa de autorização pelos responsáveis ou de desejo de participar da pesquisa. 
Cabe considerar que a pesquisadora, a primeira autora deste trabalho, não estava em posição de professora titular da turma, atuando apenas em conformidade com o que ela sugeria e produzindo o material aplicado à turma.

A coleta dos dados realizou-se mediante questionário, cujo objetivo foi elaborar um levantamento das concepções prévias dos participantes sobre a temática alimentação $e$ nutrição humana. Ressalta-se que os participantes da pesquisa já haviam tido contato com o conteúdo alimentação humana e, na oportunidade, a abordagem seguida no estudo foi a tradicional.

O questionário foi composto por 20 questões abertas, seis das quais foram analisadas neste artigo, uma vez que se mostraram mais relevantes para a presente discussão:

1. Você costuma ingerir alimentos diversificados? Você considera que isso seja importante?

2. Quais os tipos de alimentos que não poderiam faltar no seu dia a dia?

3. Substituir as refeições (café da manhã, almoço, jantar) por lanches rápidos incluindo biscoitos, salgadinhos e frituras é uma boa opção? Por quê?

4. Para você, o que é uma alimentação saudável (adequada, equilibrada)?

5. Para você, ter uma alimentação saudável (adequadalequilibrada) é importante para a saúde? Por quê?

6. Por que precisamos nos alimentar?

As respostas foram examinadas tomando por base a Análise de Conteúdo segundo o modelo de Bardin (2011). Esse método inclui um conjunto de procedimentos que descrevem o conteúdo da essência de mensagens, possibilitando inferências sobre elas (BARDIN, 2011). O corpus da análise foi as perguntas e respostas do questionário, para as quais se estabeleceram categorias e subcategorias, a posteriori.

\section{Resultados e discussão}

Para que as respostas dos estudantes pudessem ser mais bem examinadas, estas foram organizadas em arquivos por pergunta. Isto é, um arquivo incluiu uma pergunta e todas as respostas dadas a ela pelos estudantes. Após a análise inicial dos dados, estabeleceram-se categorias e subcategorias para as respostas a cada pergunta, as quais foram organizadas em quadros. Os quadros foram compostos pelas categorias definidas, as subcategorias, as respostas e os respectivos participantes que as forneceram.

As três primeiras perguntas selecionadas para discussão dos resultados abordaram sobretudo os hábitos alimentares dos alunos, ao passo que as três seguintes versavam sobre suas concepções referentes à alimentação equilibrada/adequada. 
O Quadro 1 ilustra a categorização referente à primeira pergunta (Você costuma ingerir alimentos diversificados? Você considera que isso seja importante?).

Quadro 1 - A importância do consumo de alimentos diversificados.

\begin{tabular}{|c|c|c|}
\hline CATEGORIA & RESPOSTAS & $\begin{array}{l}\text { ALUNO (No DO } \\
\text { PARTICIPANTE) }\end{array}$ \\
\hline \multirow{15}{*}{$\begin{array}{c}\text { Importância do } \\
\text { consumo de } \\
\text { alimentos } \\
\text { diversificados }\end{array}$} & $\begin{array}{l}\text { Nem todo dia diversifico os alimentos, mas isso é importante, pois muitos } \\
\text { órgãos do corpo humano precisam de alimentos diversificados. }\end{array}$ & 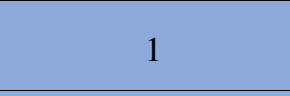 \\
\hline & $\begin{array}{l}\text { Por isso que certos alimentos são extremamente úteis ao nosso corpo, como } \\
\text { verduras; eu não consigo comer porque o gosto é horrível. }\end{array}$ & 3 \\
\hline & Isso é muito importante para que possamos conhecer sempre novos sabores. & 4 \\
\hline & Eu considero muito importante, assim temos todas as vitaminas necessárias. & 5 \\
\hline & $\begin{array}{l}\text { Acho que isso seja importante porque o corpo pede não só comer besteiras, } \\
\text { mas também verduras, frutas, etc. }\end{array}$ & 7 \\
\hline & Ingiro e acho importante pois assim meu corpo funciona bem. & 8 \\
\hline & $\begin{array}{l}\text { Porque assim absorvemos um pouco de cada nutriente, que nos } \\
\text { proporcionem força. }\end{array}$ & 9 \\
\hline & Tem que ingerir alimento saudável. & 10 \\
\hline & Porque precisamos ingerir diferentes tipos de alimentos. & 3 \\
\hline & Porque assim você não enjoa de um alimento. & 14 \\
\hline & $\begin{array}{l}\text { Porque alguns alimentos tem uma quantidade muito grande de açúcar e } \\
\text { gordura. }\end{array}$ & 2 \\
\hline & $\begin{array}{l}\text { Porque são alimentos feitos por nós, como Todinho, Nescau, refrigerante, } \\
\text { etc. }\end{array}$ & 6 \\
\hline & $\begin{array}{c}\text { Porque eu costumo ingerir alimentos diversificados como doce, e isso não é } \\
\text { bom para o nosso corpo e a saúde. Os doces podem causar problemas no } \\
\text { sangue e até a morte. }\end{array}$ & 11 \\
\hline & É uma coisa que piora a saúde. & 12 \\
\hline & Pois pode fazer algum mal há saúde. & 15 \\
\hline
\end{tabular}

Os dados apresentados no Quadro 1 indicam que alguns alunos consideram importante observar uma alimentação balanceada, enquanto outros acham que ela não é importante e mencionam, inclusive, que essa atitude faz mal à saúde.

O fato de alguns participantes acreditarem que uma alimentação balanceada não é importante deve ser sublinhado, porque o grupo de participantes foi formado por alunos cursando o final do Ensino Fundamental. Uma das possíveis explicações para esse resultado diz respeito ao fato que, em suas respostas, esses alunos consideraram alimentos que não fazem bem à saúde. Nesse sentido, o consumo destes alimentos não seria adequado, o que pode se deduzir a partir da resposta porque alguns alimentos têm uma quantidade muito grande de açúcar e gordura.

Entende-se que uma alimentação saudável deva ser variada, isto é, incluir vários grupos alimentares. Essa variedade assegura a oferta de diferentes nutrientes; além disso, essa alimentação deve ser equilibrada, já que contempla o consumo adequado de cada tipo de nutriente (BRASIL, 2009). 
Destacam-se as concepções relacionadas ao bom funcionamento do corpo. Segundo Rigui et al. (2012), os alunos dos últimos anos do ensino fundamental passam a entender que os alimentos são úteis ao corpo e, mais especificamente, aos órgãos. As concepções relacionadas à absorção de nutrientes que proporcionam força e ao aporte adequado de vitaminas indicam a importância da ingestão de nutrientes variados, o que concorda com os dados apresentados no Quadro 1, os quais indicam que os alunos têm a noção de que uma alimentação adequada deve ser diversificada.

Ingerir diferentes tipos de alimentos revela se, de fato, o aluno quis se referir a alimento ou nutriente, o que indica a inconstância conceitual associada aos dois termos. Essa confusão conceitual também foi observada na pesquisa de Costa (2013), na qual os participantes entendem alimentos como sendo nutrientes, demostrando entendimento impreciso com relação ao que é um nutriente e o que seria a fonte dele.

Na segunda pergunta (Quais tipos de alimentos que não poderiam faltar no seu dia a dia?) estabeleceu-se a categorização representada no Quadro 2.

Quadro 2 - Os alimentos que não poderiam faltar no dia a dia.

\begin{tabular}{|c|c|c|}
\hline CATEGORIA & RESPOSTAS & $\begin{array}{l}\text { ALUNO ( } \mathbf{N}^{\circ} \text { DO } \\
\text { PARTICIPANTE) }\end{array}$ \\
\hline \multirow{15}{*}{$\begin{array}{l}\text { Alimentos que } \\
\text { não poderiam } \\
\text { faltar no dia a } \\
\text { dia }\end{array}$} & Arroz, feijão, carne, alface e umas frutas. & 1 \\
\hline & $\begin{array}{l}\text { O feijão e o arroz, porque eles dois juntos já têm todos os nutrientes de que o } \\
\text { nosso corpo necessita. Fora as frutas e verduras. }\end{array}$ & 2 \\
\hline & Arroz, bife ou carne, doces, porque eu gosto muito. & 3 \\
\hline & $\begin{array}{l}\text { Comida de verdade, como: leite, frutas, legumes, saladas, ovos e esse tipo de } \\
\text { coisa, pois elas nos fornecem nutrientes e vitaminas. }\end{array}$ & 4 \\
\hline & Frutas, legumes, proteínas, etc. Como: maçã, banana, cenoura, carne, etc. & 5 \\
\hline & Café da manhã, almoço e jantar. Porque são alimentos para o nosso dia a dia. & 6 \\
\hline & Arroz, feijão, frutas, doce, etc. & 7 \\
\hline & $\begin{array}{l}\begin{array}{l}\text { Frutas, verduras, carnes, etc., pois sem eles nosso corpo não funcionaria } \\
\text { direito. }\end{array} \\
\end{array}$ & 8 \\
\hline & $\begin{array}{l}\text { Os tipos de alimentos que têm todos os tipos de nutrientes (carboidratos, } \\
\text { proteínas, lipídios, sais minerais). }\end{array}$ & 9 \\
\hline & $\begin{array}{l}\text { Feijão, salada porque feijão tem bastante ferro e salada tem bastante ferro e } \\
\text { proteínas. }\end{array}$ & 10 \\
\hline & O feijão e a salada, são os mais com puras vitaminas para nossa saúde e vida. & 11 \\
\hline & Frutas, proteína, carboidratos, porque são importantes para nosso dia a dia. & 12 \\
\hline & $\begin{array}{l}\text { Salada, arroz, carne, entre outros, pois os alimentos que mais estão presentes } \\
\text { nas minhas refeições. }\end{array}$ & 13 \\
\hline & $\begin{array}{l}\text { Feijão, arroz, carne, salada e refrigerante porque é um alimento que me deixa } \\
\text { satisfeito para um dia inteiro de trabalho e brincadeiras. }\end{array}$ & 14 \\
\hline & $\begin{array}{c}\text { Frutas, saladas, legumes, carboidratos, lipídios, etc. Pois são importantes para a } \\
\text { saúde e são gostosos. }\end{array}$ & 15 \\
\hline
\end{tabular}


As respostas reproduzidas no Quadro 2 revelam a dificuldade conceitual dos alunos em diferenciar dois conceitos importantes, o de alimento e o de nutriente, pois essas duas palavras são apresentadas por eles como sinônimos. Esse achado foi também discutido por Zompero et al. (2017) em um estudo que constatou que muitos estudantes ainda confundem nutrientes com alimentos.

No entanto "segundo as ciências nutricionais, alimentos e nutrientes não são sinônimos" (SODRÉ; MATTOS, 2013). Os nutrientes podem ser definidos como compostos químicos que constituem os alimentos e são utilizados pelo organismo para a manutenção das funções vitais e o crescimento (BRASIL, 2009).

A confusão conceitual apresentada pode ocorrer pois, no cotidiano e nos mais diversos ambientes, “[...] o nutrir ou o alimentar são 'palavras' que circulam na nossa cultura mais ou menos como sinônimos" (CARVALHO et al., 2011, p. 156). Além disso, “a linguagem cotidiana é o modo mais abrangente de se compartilhar significados e permite a comunicação entre os vários grupos especializados dentro de uma mesma língua" (MORTIMER, 1996, p. 26).

Nas respostas dadas à segunda pergunta, entre os alimentos mais citados como indispensáveis ao dia a dia estão a carne, o arroz e o feijão. Estes pertencem aos grupos carboidratos e proteínas e entram na composição do prato mais frequentemente visto na mesa dos brasileiros. A carne também foi o alimento mais mencionado por alunos no estudo de Bizzio et al. (2009). Já na pesquisa realizada por Rodrigues et al. (2011), os alimentos mais citados pelos alunos foram o arroz e o feijão. As verduras e os legumes, assim como em Rigui et al. (2011), foram menos referidos como alimentos que não poderiam faltar no dia a dia.

Um dado relevante foi o fato de o refrigerante aparecer entre os alimentos essenciais citados pelos alunos. Tal achado assinala a falta de compreensão sobre o prejuízo que esse tipo de bebida causa à saúde, conforme observado em dados de pesquisas anteriores sobre o tema (MOLIN; SOARES, 2016; PEREIRA et al., 2017).

Ao lado do uso rotineiro de outras bebidas calóricas, como os sucos artificiais, o refrigerante apresenta-se como um item inadequado na alimentação de crianças e adolescentes. Essa classe de bebidas tem o potencial de causar diversos problemas de saúde; mesmo assim, percebe-se que o consumo de refrigerantes é citado como item comum no cardápio de muitos jovens (CARVALHO; MACHADO, 2014).

Além do refrigerante e das bebidas adocicadas, é comum a substituição de uma refeição tradicional por lanches com altos teores calóricos e quantidades elevadas de sal, açúcar e gorduras. Esses lanches não oferecem os nutrientes essenciais para uma alimentação que promova a saúde (CARVALHO; MACHADO, 2014). 
Com base no elevado consumo de lanches entre adolescentes e jovens e no fato de que esses lanches, por vezes, acabam compondo ou mesmo substituindo as principais refeições diárias, destaca-se como relevante a terceira pergunta aplicada aos estudantes, Substituir as refeições (café da manhã, almoço, jantar) por lanches rápidos incluindo biscoitos, salgadinhos e frituras é uma boa opção? Por quê? Apenas um aluno respondeu afirmativamente a essa pergunta. Nesse caso, a categorização foi realizada a partir das justificativas apresentadas nas respostas, as quais estão representadas no Quadro 3.

Quadro 3 - A substituição das refeições por lanches.

\begin{tabular}{|c|c|c|c|}
\hline CATEGORIA & $\begin{array}{c}\text { SUBCATEGORIAS } \\
\text { PRIMÁRIAS }\end{array}$ & RESPOSTAS & \begin{tabular}{|c|} 
ALUNO ( ${ }^{\circ}$ DO \\
PARTICIPANTE) \\
\end{tabular} \\
\hline \multirow{15}{*}{$\begin{array}{r}\text { Substituição } \\
\text { das refeiçôes } \\
\text { por lanches }\end{array}$} & \multirow{14}{*}{ Não é uma boa opção } & $\begin{array}{l}\text { Não, pois lanches rápidos não nos deixam fortes para o resto do dia } \\
\text { como um prato de feijão. }\end{array}$ & 1 \\
\hline & & $\begin{array}{c}\text { Não, porque o lanche que você pode comer ao invés de uma refeição } \\
\text { não teria todos os nutrientes necessários para as necessidades do } \\
\text { corpo. }\end{array}$ & 2 \\
\hline & & $\begin{array}{l}\text { Não, porque café da manhã, almoço e janta são necessários ao nosso } \\
\text { corpo, e lanches gordurosos ou biscoitos não têm o que precisamos. }\end{array}$ & 3 \\
\hline & & $\begin{array}{l}\text { Não, pois esses alimentos fazem mal para a saúde e não nos } \\
\text { fornecem os nutrientes que nós precisamos }\end{array}$ & 4 \\
\hline & & $\begin{array}{l}\text { Não é, pois biscoitos, salgadinhos e frituras não são saudáveis e não } \\
\text { têm todas as vitaminas de que precisamos. }\end{array}$ & 5 \\
\hline & & $\begin{array}{l}\text { Não porque não são alimentos próprios para o corpo. Por que são } \\
\text { salgados e frituras isso é muito ruim para o nosso corpo humano. }\end{array}$ & 6 \\
\hline & & $\begin{array}{c}\text { Não porque o nosso corpo precisa de uma alimentação saudável para } \\
\text { o bom desenvolvimento do nosso corpo. }\end{array}$ & 7 \\
\hline & & $\begin{array}{c}\text { Não, pois nosso corpo fica sem algumas substâncias e não funciona } \\
\text { bem. }\end{array}$ & 8 \\
\hline & & Não, pois não dá todos os nutrientes que o corpo precisa. & 9 \\
\hline & & $\begin{array}{c}\text { Não é certo, porque em vez de jantar uma coisa mais leve que faz } \\
\text { bem para o corpo a gente acaba ingerindo coisas não apropriadas } \\
\text { para o nosso bem. }\end{array}$ & 11 \\
\hline & & Não porque não vai substituir todos os nutrientes do café da manhã. & 12 \\
\hline & & $\begin{array}{l}\text { Não, pois não estaria nos dando fonte de energia suficiente como um } \\
\text { almoço, mas muitas pessoas fazem isso, por causa da correria do dia } \\
\text { a dia. }\end{array}$ & 13 \\
\hline & & $\begin{array}{c}\text { Não porque esses alimentos contem açúcar sal fritura coisas que } \\
\text { fazem muito mau a saúde. }\end{array}$ & 14 \\
\hline & & $\begin{array}{l}\text { Não pois as frituras e salgadinhos podem nos fazer mal e não } \\
\text { podemos substituir pois são as principais refeições. }\end{array}$ & 15 \\
\hline & É uma boa opção & $\begin{array}{l}\text { Sim é uma boa opção porque nós precisamos nos alimentar para ter } \\
\text { uma saúde boa. }\end{array}$ & 10 \\
\hline
\end{tabular}

As respostas reproduzidas no Quadro 3 atestam que os alunos participantes da pesquisa demonstraram determinado discernimento a respeito de os lanches não serem uma boa opção de alimentação e representarem um substituto adequado às refeições. As respostas destacaram os lanches como alternativas inadequadas para a saúde, destituídas dos constituintes essenciais ao organismo. 
Apesar disso, um estudante alimentava a ideia de que substituir uma refeição por um lanche seja uma boa opção. Carvalho e Machado (2014) constataram o elevado consumo de lanches por adolescentes e jovens, fator este que desequilibra as dietas desses indivíduos.

Além do costume de substituir as refeições por lanches, os adolescentes têm o hábito de saltá-las. De acordo com o estudo de Gasior et al. (2016) sobre os hábitos alimentares dos jovens, entre as três refeições básicas, o almoço se apresentou como a mais consumida. Porém, os autores sublinham que a observância dessa refeição diária diminuiu com o aumento da idade escolar, principalmente entre as meninas; já o café da manhã foi a refeição mais saltada. A prática do desjejum pode estar relacionada com fatores como "não gostar, não ter tempo, não ter apetite e despertar altas horas da manhã" (SILVA et al., 2015a, p. 3302).

O costume de não ingerir café da manhã pode levar a uma inadequação na relação entre estatura e idade. Vale o mesmo para a relação entre o Índice de Massa Corporal e a idade do indivíduo, o qual indica que tais hábitos estão relacionados com o estado nutricional, mostrando a maior vulnerabilidade destes indivíduos (PEDRAZA et al., 2017).

Quanto às concepções sobre alimentação equilibrada, perguntou-se aos estudantes, Para você, o que é uma alimentação saudável (adequada, equilibrada)?

A categoria e as subcategorias de respostas são dadas no Quadro 4.

Quadro 4 - As concepções de alimentação saudável.

\begin{tabular}{|c|c|c|c|}
\hline CATEGORIA & $\begin{array}{c}\text { SUBCATEGORIAS } \\
\text { PRIMÁRIAS }\end{array}$ & RESPOSTAS & $\begin{array}{l}\text { ALUNO ( } \mathbf{N}^{\circ} \text { DO } \\
\text { PARTICIPANTE) }\end{array}$ \\
\hline \multirow[t]{11}{*}{$\begin{array}{l}\text { Concepções de } \\
\text { alimentação } \\
\text { saudável }\end{array}$} & \multirow[t]{10}{*}{$\begin{array}{c}\text { Possuir os } \\
\text { nutrientes/alimentos } \\
\text { necessários }\end{array}$} & $\begin{array}{l}\text { Uma alimentação saudável se baseia em pratos mais } \\
\text { diversificados, com: carboidratos, proteínas, nutrientes, } \\
\text { lipídios, água, vitaminas e sais minerais. }\end{array}$ & ( \\
\hline & & \begin{tabular}{|c|} 
Para mim, uma alimentação saudável, seria aquela que \\
possuísse todos os nutrientes necessários para o bem-estar: o \\
carboidrato, lipídio, proteína, sais minerais e vitaminas.
\end{tabular} & 2 \\
\hline & & $\begin{array}{c}\text { É uma refeição que contenha todos os nutrientes necessários } \\
\text { ao nosso corpo (vitaminas, lipídios, carboidratos, sais } \\
\text { minerais e proteína). }\end{array}$ & 3 \\
\hline & & $\begin{array}{l}\text { Uma alimentação provida de todos os nutrientes comida de } \\
\text { verdade, não coisas embaladas. }\end{array}$ & 4 \\
\hline & & $\begin{array}{l}\text { Uma alimentação saudável para mim é que contenha } \\
\text { legumes, verduras, e que tenha todos os nutrientes } \\
\text { necessários. }\end{array}$ & 5 \\
\hline & & $\begin{array}{l}\text { Com vários tipos de alimentos, exemplo: verduras, frutas, } \\
\text { arroz, feijão, carne branca e um pouco de carne vermelha. }\end{array}$ & 7 \\
\hline & & $\begin{array}{c}\text { Uma alimentação variada com carboidratos, lipídios, } \\
\text { vitaminas e sais minerais. }\end{array}$ & 8 \\
\hline & & Tem que ingerir alimento saudável. & 9 \\
\hline & & $\begin{array}{l}\text { Alimentação saudável pra mim é uma alimentação boa, é } \\
\text { aquela alimentação com vitaminas, uma alimentação mais } \\
\text { leve. }\end{array}$ & 11 \\
\hline & & $\begin{array}{c}\text { Para mim uma alimentação saudável é uma alimentação com } \\
\text { todos os nutrientes necessários. }\end{array}$ & 12 \\
\hline & Que faça bem para a & Para mim alimentação saudável é aquela que traz para saúde & 10 \\
\hline
\end{tabular}




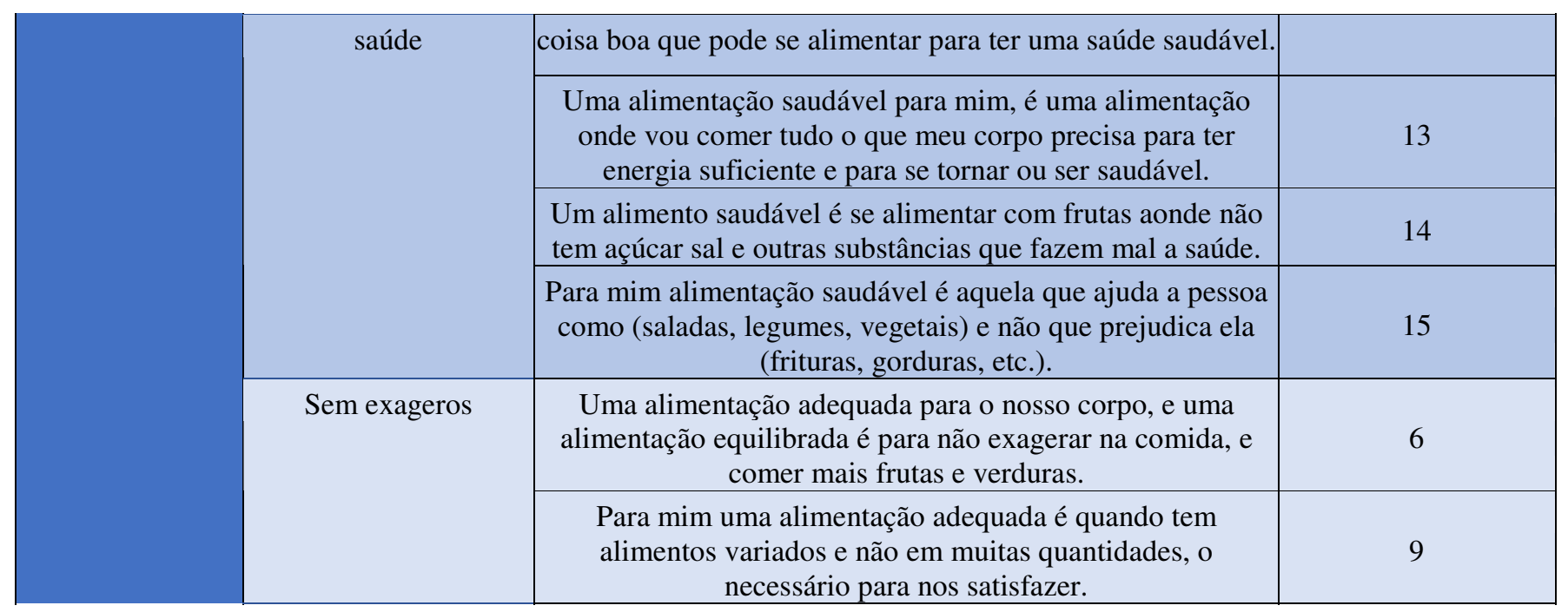

Sobre as concepções de alimentação equilibrada, foram selecionadas três das perguntas aplicadas. As concepções de estudantes a respeito de um assunto são uma indicação do andamento do ensino e aprendizagem. O exame dessas concepções pode ser visto como processo de aferição, ou verificação, pois produz indícios sobre as imprecisões nelas contidas (CARVALHO et al., 2011).

A amplitude das respostas dos alunos mostradas no Quadro 4, as quais abrangeram vários tipos de alimentos e nutrientes, indica que os alunos participantes nutrem a ideia de diversidade. Isso pode ser indício de que, em suas concepções, uma alimentação equilibrada é aquela que é variada. Na pesquisa de Toral et al. (2009), a variedade alimentar também se manifestou na concepção que os adolescentes participantes tinham de alimentação saudável.

Nessa pergunta percebe-se que os alimentos reguladores se sobressaíram ante os demais. Os mais citados foram as verduras, as frutas e os legumes; foram também mencionados os sais minerais e as vitaminas, dos quais aqueles alimentos são fontes. As subcategorias primárias que faça bem para a saúde e sem exageros expressam concepções adequadas quanto a alimentação saudável.

Os dados apresentados no Quadro 4 confirmam os do Quadro 2, o qual indica determinado grau de imprecisão na diferenciação entre os termos alimento e nutriente, pois, novamente, os alunos os usam como sinônimos. Esse dado acentua a necessidade de que a distinção entre esses conceitos deva ser enfatizada no ensino de Ciências como meio de possibilitar aos alunos a competência em diferenciá-los de maneira independente toda vez que os termos são utilizados.

As respostas dadas à pergunta Para você, ter uma alimentação saudável (adequadalequilibrada) é importante para a saúde? Por quê? e a categorização delas são dadas no Quadro 5. 
Quadro 5 - A importância de uma alimentação saudável.

\begin{tabular}{|c|c|c|c|}
\hline CATEGORIA & $\begin{array}{l}\text { SUBCATEGORIAS } \\
\text { PRIMÁRIAS }\end{array}$ & RESPOSTAS & $\begin{array}{l}\text { ALUNO (No DO } \\
\text { PARTICIPANTE) }\end{array}$ \\
\hline \multirow{15}{*}{$\begin{array}{l}\text { Importância de } \\
\text { uma alimentação } \\
\text { saudável }\end{array}$} & \multirow[t]{7}{*}{$\begin{array}{c}\text { Evitar/prevenir } \\
\text { doenças e ter saúde }\end{array}$} & $\begin{array}{c}\text { Sim, porque se você comer muito carboidrato ou lipídio pode } \\
\text { causar diabete, entupir veias, etc. }\end{array}$ & 2 \\
\hline & & $\begin{array}{c}\text { Sim é importante, sem uma alimentação saudável podemos } \\
\text { ter doenças, falta de vitaminas, etc. }\end{array}$ & 5 \\
\hline & & $\begin{array}{l}\text { Sim é importante uma alimentação saudável para a saúde } \\
\text { porque sem alimentação saudável nossa saúde não vai ser } \\
\text { boa. }\end{array}$ & 10 \\
\hline & & $\begin{array}{l}\text { Sim, porque as outras alimentações não adequada ela não faz } \\
\text { bem para o nosso corpo, e a alimentação saudável nos deixa } \\
\text { muito bem, então a alimentação saudável é muito importante } \\
\text { para nossa saúde. }\end{array}$ & 11 \\
\hline & & Sim porque não tem risco de sua saúde piorar. & 12 \\
\hline & & $\begin{array}{l}\text { Sim porque a alimentação saudável é aquela que não faz mau } \\
\text { a saúde e o meio ambiente. }\end{array}$ & 14 \\
\hline & & Sim pois ajuda no desenvolvimento da pessoa, na saúde, etc. & 15 \\
\hline & \multirow[t]{4}{*}{$\begin{array}{l}\text { Bom funcionamento } \\
\text { do corpo }\end{array}$} & $\begin{array}{l}\text { Sim, pois o nosso corpo precisa de certas substâncias para } \\
\text { funcionar bem. }\end{array}$ & 3 \\
\hline & & $\begin{array}{l}\text { Sim para o nosso corpo, organismo funcionarem bem da } \\
\text { forma adequada deixando o nosso corpo nutrido. }\end{array}$ & 7 \\
\hline & & $\begin{array}{l}\text { Sim, pois assim não falta nada em nosso corpo e o nosso } \\
\text { organismo funciona direito. }\end{array}$ & 8 \\
\hline & & $\begin{array}{l}\text { Sim, porque quando temos uma alimentação saudável o } \\
\text { nosso corpo também vai ser saudável. }\end{array}$ & 13 \\
\hline & $\begin{array}{l}\text { Regulagem do peso e } \\
\text { massa corporal }\end{array}$ & Sim, para a regulagem do peso e da massa corporal. & 1 \\
\hline & Ter mais disposição & $\begin{array}{l}\text { Sim, porque nos ajuda a ter mais disposição, para realizar as } \\
\text { tarefas diárias, além de prevenir doenças. }\end{array}$ & 9 \\
\hline & $\begin{array}{l}\text { Para ficar forte e ser } \\
\text { feliz }\end{array}$ & $\begin{array}{l}\text { Porque certos tipos de alimentos previnem certos tipos de } \\
\text { doenças, nos deixam mais fortes e felizes. }\end{array}$ & 4 \\
\hline & Para evitar exageros & $\begin{array}{l}\text { Sim, porque se nós comermos coisas gordurosas balas e } \\
\text { outras coisas, assim come uma coisa adequada e não } \\
\text { exagerada. }\end{array}$ & 6 \\
\hline
\end{tabular}

A partir do Quadro 5 nota-se certa ênfase na relação da alimentação saudável com questões relativas à saúde ou doenças e com o bom funcionamento do corpo. Esse achado é promissor, se considerarmos a importância da conscientização sobre esse aspecto. É relevante observar que os alunos, com base nessas concepções, desenvolvem a capacidade de posicionar-se de forma consciente ante questões referentes à saúde alimentar. Em última análise, isso significa que esses alunos são menos vulneráveis aos apelos da mídia que induzem ao consumo de alimentos de baixo valor nutricional e valorizam padrões idealizadores de beleza (GONZÁLEZ; PALEARI, 2006).

Por outro lado, o conhecimento sobre doenças ocasionadas pela má alimentação não é garantia de modificação positiva nos hábitos. Por essa razão, é importante que a escola seja o lugar de práticas educativas específicas que conduzam os discentes a experimentar e apreciar alimentos saudáveis (LOBO et al., 2013). 
Destaca-se que uma resposta como ser feliz demonstra o pouco entendimento da importância dos bons hábitos alimentares, enquanto concepções como evitar doenças e regulagem de peso e massa corporal revelam uma perspectiva mais aprofundada da temática. As respostas categorizadas dadas à última pergunta selecionada (Por que precisamos nos alimentar?) são mostradas no Quadro 6.

Quadro 6 - Por que precisamos nos alimentar?

\begin{tabular}{|c|c|c|c|}
\hline CATEGORIA & $\begin{array}{l}\text { SUBCATEGORIAS } \\
\text { PRIMÁRIAS }\end{array}$ & RESPOSTAS & $\begin{array}{l}\text { ALUNO ( }{ }^{\circ} \text { DO } \\
\text { PARTICIPANTE) }\end{array}$ \\
\hline \multirow{17}{*}{$\begin{array}{l}\text { Por que } \\
\text { precisamos nos } \\
\text { alimentar }\end{array}$} & \multirow{4}{*}{$\begin{array}{l}\text { Para ter } \\
\text { saúde/prevenir } \\
\text { doenças }\end{array}$} & Para conseguirmos realizar nossas tarefas, prevenir doenças. & 9 \\
\hline & & $\begin{array}{l}\text { Precisamos nos alimentar para ter uma saúde boa para não } \\
\text { ter nenhum tipo de problema na saúde. }\end{array}$ & 10 \\
\hline & & $\begin{array}{l}\text { Porque uma alimentação saudável (boa) a gente tem que } \\
\text { comer para ficarmos bem com a nossa saúde e ficarmos bem } \\
\text { no dia a dia. }\end{array}$ & 11 \\
\hline & & Para podermos ter saúde. & 15 \\
\hline & \multirow[t]{4}{*}{ Para ter energia } & $\begin{array}{l}\text { Para que possamos ter energia, para o nosso corpo funcionar } \\
\text { corretamente e para não ficar com fome. }\end{array}$ & 4 \\
\hline & & É preciso para ter energia para nosso dia a dia. & 5 \\
\hline & & $\begin{array}{c}\text { Para termos energia para as células do nosso corpo } \\
\text { continuarem vivas. }\end{array}$ & 8 \\
\hline & & Para termos força (energia). & 13 \\
\hline & \multirow[t]{5}{*}{ Para não morrermos } & Para não morrermos. & 2 \\
\hline & & Para sobreviver. & 12 \\
\hline & & $\begin{array}{l}\text { Para que nós ficamos fortes dispostos para tudo e para não } \\
\text { ficar doente que sem alimento nos morremos. }\end{array}$ & 14 \\
\hline & & $\begin{array}{l}\text { Pois sem os alimentos não conseguimos finalizar tarefas que } \\
\text { precisam de força braçal. }\end{array}$ & 1 \\
\hline & & $\begin{array}{c}\text { Por que é a partir do alimento que o nosso corpo funciona, } \\
\text { necessitamos dele. }\end{array}$ & 3 \\
\hline & & Para o bom desenvolvimento do nosso corpo. & 7 \\
\hline & Para realizar tarefas & Para conseguirmos realizar nossas tarefas, prevenir doenças. & 9 \\
\hline & $\begin{array}{l}\text { Para pensar e prestar } \\
\text { atenção }\end{array}$ & $\begin{array}{c}\text { Porque sem alimentos não conseguimos pensar nas coisas, } \\
\text { não prestamos atenção o que a pessoa fala. }\end{array}$ & 6 \\
\hline & $\begin{array}{l}\text { Para ficar forte e } \\
\text { disposto }\end{array}$ & $\begin{array}{l}\text { Para que nós ficamos fortes dispostos para tudo e para não } \\
\text { ficar doente que sem alimento nos morremos. }\end{array}$ & 14 \\
\hline
\end{tabular}

No Quadro 6, variáveis relativas a saúde e doenças novamente tiveram destaque. Evidenciaram-se também os fatores referentes ao ganho de energia, indicando uma melhor compreensão sobre o tema. Novamente, destacam-se algumas concepções mais distanciadas dos conceitos científicos associados à temática, como para não morrermos.

As subcategorias primárias para realizar tarefas, para pensar e prestar atenção e para ficar forte e disposto explicitam a necessidade da alimentação para a execução de atividades. Já as subcategorias primárias para o corpo funcionar bem e para ter energia indicam a o papel essencial da alimentação na manutenção de atividades vitais.

Os resultados obtidos para esta pergunta assemelham-se aos achados discutidos no estudo de González e Paleari (2006). Na pesquisa realizada com alunos entre 14 e 18 anos de idade na cidade de Botucatu, estado de São Paulo, os autores observaram que os estudantes 
conferem aos alimentos atribuições como fonte de energia, força e disposição, e que os alimentos são necessários para evitar problemas de saúde, a fome e a morte.

Entender a função do alimento no organismo humano e conhecer as quantidades e os nutrientes fundamentais ao equilíbrio alimentar são fatores essenciais que devem ser construídos com os estudantes. É a partir destes conhecimentos que será possível compreender o porquê e como se alimentar corretamente, visando a uma melhor qualidade de vida e à manutenção da saúde. Nesse contexto, o papel da escola torna-se imprescindível como fonte de informações e local de ações dirigidas à conscientização sobre alimentação saudável, no que se consolida como educação nutricional (PEDRAZA et al., 2017).

Salienta-se o engajamento necessário entre a escola e a família. Os dois grupos precisam trabalhar ações em conjunto, em prol da conscientização sobre bons hábitos alimentares. A influência familiar é muito forte quando se trata da alimentação. Ainda que sejam trabalhados os aspectos e as variáveis da nutrição equilibrada na escola, é em casa que crianças e adolescentes têm experiências cotidianas importantes com a alimentação.

Nessa perspectiva, é essencial entender que as aulas de Ciências, no que se refere à temática alimentação e nutrição humanas, deve ir além dos aspectos referentes a hábitos alimentares adequados. A escola precisa ser palco de ampliação desse debate, o qual deve abordar também os fatores referentes aos conhecimentos que os estudantes trazem consigo, incluindo a realidade social e os contextos nos quais vivem (LOBO et al., 2013). Essa ampliação da discussão é peça chave na mudança positiva dos hábitos alimentares destes sujeitos.

Poulain e Proença (2003, p. 254) acentuam a existência dos conceitos de espaço social alimentar e modelo alimentar, os quais podem oportunizar "e criar condições de aplicação de um diálogo pluridisciplinar com as ciências da alimentação e da nutrição". Nesse sentido, é essencial considerar a multidimensionalidade dos aspectos referentes às escolhas alimentares com potencial de enriquecer esse debate. A discussão sobre os papéis e a influência que os conhecimentos biológicos e os saberes sociais exercem é um caminho para entender e alterar escolhas alimentares. A abordagem às dimensões sociais da alimentação permite pensar a interação entre os campos biológico, social e psicológico.

Assim, é a partir de uma visão integradora que os estudantes têm a possibilidade de expandir significados em sua aprendizagem (BIZZIO et al., 2009). Silva et al. (2015b) apontam a construção de hortas escolares como prática capaz de proporcionar e problematizar a educação alimentar na escola. Uma horta atua como ponto de referência para a reflexão sobre a importância do consumo de verduras e legumes em prol de melhores hábitos alimentares. Além disso, essa reflexão possibilita o entendimento sobre os impactos que a forma de cultivo pode trazer para a saúde, tanto de quem produz, como de quem consome. 
No entanto, não cabe apenas ter em vista o ensino de Ciências em favor da conscientização sobre práticas alimentares. É necessário que se amplie este entendimento, levando em conta a influência de outros fatores condicionantes dessas escolhas, como os aspectos sociais com influência na alimentação.

As interações entre o social e o biológico se caracterizam por fatores como a influência dos contextos sociais, por exemplo, se considerarmos a alimentação como aprendizagem social, relacionada aos grupos em que as pessoas estão inseridas. Esses grupos têm seus próprios hábitos e costumes, os quais vão além da questão do certo ou errado, estando associados à identidade social de uma coletividade (POULAIN; PROENÇA, 2003).

Logo, não cabe apenas condicionar as escolhas e hábitos alimentares a partir da esfera biológica. É essencial atentar para os demais fatores que influenciam essas escolhas.

\section{Considerações finais}

Considerando o objetivo de investigar as concepções de uma turma de estudantes do oitavo ano do Ensino Fundamental a respeito de seus hábitos alimentares e alimentação equilibrada por meio de questionário, os resultados do presente estudo destacam alguns aspectos significativos.

Quantos aos hábitos alimentares, as respostas dos estudantes evidenciam certo grau de entendimento sobre a importância de uma alimentação balanceada para a saúde. Os resultados discutidos também indicam que os estudantes estão conscientes dos problemas associados ao consumo de lanches rápidos em substituição às refeições.

Os alunos apresentaram diversas concepções sobre alimentação equilibrada, algumas das quais se manifestaram como conceitos espontâneos. Contudo, os participantes também expressaram concepções calcadas em uma relação mais precisa com os conceitos científicos associados, os quais remeteram à a ideia de alimentação balanceada. No entanto, cabe ressaltar a confusão conceitual demonstrada por alunos que atribuíram significado idêntico aos termos alimento e nutriente.

Além disso, algumas concepções se mostraram frágeis quanto à temática investigada, sublinhado a necessidade de aprofundar a temática no ambiente escolar. As respostas dadas às duas últimas perguntas escolhidas para discussão neste artigo (Para você, ter uma alimentação saudável [adequadalequilibrada] é importante para a saúde? Por quêe? e Por que precisamos nos alimentar?) revelam que os alunos estão cientes de que hábitos alimentares influenciam a saúde e a aquisição de doenças.

Independentemente de estarem alinhadas a conceitos científicos ou serem de caráter mais subjetivo, todas as concepções apresentadas pelos alunos sobre alimentação equilibrada e os próprios hábitos alimentares devem ser consideradas no cenário escolar da educação 
alimentar. Essas concepções servem de suporte para transformações de hábitos e aquisição de novos conhecimentos. Tais concepções, apesar de frágeis, apontam para um caminho de construção de elos entre conhecimentos prévios e conhecimentos científicos.

No entanto, mais do que problematizar a alimentação no sentido de conscientização das práticas, é essencial também aprofundar o entendimento sobre os fatores sociais interconectados com os fatores biológicos e psicológicos que, de igual maneira, atuam na construção dos hábitos alimentares dos adolescentes. Este estudo contribui com a discussão sobre esses aspectos, enriquecendo o debate sobre alimentação equilibrada.

Os tópicos abordados neste artigo, referentes aos hábitos e concepções alimentares dos discentes, precisam ser continuamente dialogados e aperfeiçoados no ensino de Ciências. É a partir da aproximação entre essas percepções subjetivas e os conceitos científicos que novos e significativos avanços na conscientização e na construção de hábitos saudáveis se materializam na vida do estudante, hábitos esses que poderão acompanhá-lo ao longo da vida.

Para isso, há que se pensar em estratégias que possibilitem a mudança dos hábitos alimentares dos alunos, como a análise reflexiva de suas dietas, por exemplo, com o objetivo de enfatizar a importância de uma alimentação adequada para uma boa qualidade de vida.

\section{Referências}

BARDIN, L. Análise de Conteúdo. São Paulo: Edições 70, 2011.

BIZZIO, M. A.; VÁZQUEZ, S.; PEREIRA, R.; NÚÑEZ, G. Una indagación sobre la vinculación que realizan los alumnos entre su alimentación y el consumo energético. Revista Electrónica de Enseñanza de las Ciências, v. 8, n. 3, p. 1037-1053, 2009.

BORGES, E. M.; SANTOS, D. R.; SILVA, J. L.; SANTOS, S. S.; MAGALHÃES, E. M. Percepções dos hábitos alimentares dos estudantes de uma escola de ensino fundamental do município de Jaciara/MT. Monografias Ambientais - REMOA. v. 14, p. 89-100, 2015.

BRASIL. Secretaria de Educação Fundamental. Parâmetros curriculares nacionais: ciências naturais. Brasília: MEC/SEF, 1998.

BRASIL. Ministério da Educação. Secretaria da Educação Básica. Alimentação saudável e sustentável. Brasília: Universidade de Brasília, 2009.

BRASIL. Ministério da Educação. Base Nacional Comum Curricular. 2017.

CARDOSO, C. R.; BELO, L. O. Promoção de hábitos alimentares saudáveis na infância através do ensino de Ciências Naturais. In: ENCONTRO NACIONAL DE PESQUISA EM EDUCAÇÃO EM CIÊNCIAS, 10., 2015. Águas de Lindóia/SP. Atas...Águas de Lindoia, 2015.

CARVALHO, D. S.; MACHADO, V. M. Hábitos alimentares e nutricionais de jovens do ensino médio em uma escola de Campo Grande/MS. Revista da SBEnBio, n. 7, p. 1483-1494, out $/ 2014$. 
CARVALHO, M. C. V. S.; LUZ, M. T.; PRADO, S. D. Comer, alimentar e nutrir: categorias analíticas instrumentais no campo da pesquisa científica. Ciência e Saúde Coletiva, v. 16, n. 1, p. 155-163, 2011.

COSTA, R. R. As concepções dos alunos do $8^{\circ}$ ano sobre nutrientes. In: CONGRESSO NACIONAL DE EDUCAÇÃO, 11, Curitiba/Paraná, 2013. Anais...Curitiba, 2013.

ELIAS, R. C.; FONSECA, A. B. C. Um olhar sobre a produção científica na área da Nutrição a partir de uma perspectiva CTS: apontamentos para a formação superior em saúde.

Alexandria Revista de Educação em Ciência e Tecnologia, v. 2, n. 1, p. 109-135, 2009.

ERCAN, O. The effects of multimedia learning material on students' academic achievement and attitudes towards science courses. Journal of Baltic Science Education, v. 13, n. 5, p. 608$621,2014$.

ESTEBAN, M. P. S. Pesquisa qualitativa em educação: fundamentos e tradições. Tradução Miguel Cabrera. Porto Alegre: AMGH, 2010.

FAN, M.; JIN, Y. The effects of weight perception on adolescents' weight-loss intentions and behaviors: evidence from the youth risk behavior surveillance survey. International Journal of Environmental Research and Public Health, n. 12, p. 14640-14668, 2015.

FREITAS, D. L. O. Comportamento alimentar em estudantes de nutrição e a desejabilidade social enquanto confundidor. Dissertação de Mestrado. Universidade do Porto. 2016.

GASIOR, A. O.; PIWOWAR, M.; KWIATKOWSKI, J.; KASPERCZYK, J.;

LEWANDOWSKA, A. S. Breakfast and other meal consumption in adolescents from Southern Poland. International Journal of Environmental Research and Public Health, n. 13, p. 1-10, 2016.

GIL, A. C. Como elaborar projetos de pesquisa. 4.ed. São Paulo: Atlas, 2002.

GIORGI, V. V. Adentrando o "espaço social alimentar": sociologias da alimentação, por Jean-Pierre Poulain. Dimetria, v. 10, n. 3, p. 729-738, 2015.

GONZÁLEZ, F. G.; PALEARI, L. M. O ensino da digestão-nutrição na era das refeições rápidas e do culto ao corpo. Ciência \& Educação, v. 12, n. 1, p. 13-24, 2006.

GREENWOOD, S. A.; FONSECA, A. B. Espaços e caminhos da educação alimentar e nutricional no livro didático. Ciência \& Educação, v. 6, n. 2, p. 201-208, 2016.

KLOTZ-SILVA, J.; PRADO, S. D.; SEIXAS, C. M. Comportamento alimentar no campo da Alimentação e Nutrição: do que estamos falando? Physis Revista de Saúde Coletiva, v. 26, n. 4, p. 1103-1123, 2016.

LOBO, M.; AZEVEDO, T.; MARTINS, I. O conhecimento científico como recurso para a educação alimentar em aulas de ciências: limites e (im) possibilidades. In: ENCONTRO NACIONAL DE PESQUISA EM EDUCAÇÃO EM CIÊNCIAS, 9., 2013. Águas de Lindoia/SP. Atas... Águas de Lindoia, 2013.

LOBO, M.; MARTINS, I. Representações sobre alimentação e ciência em um texto de divulgação científica: implicações para a educação em ciências. Alexandria Revista de Educação em Ciência e Tecnologia, v. 6, n. 3, p. 3-26, 2013. 
MOLIN, V. T. S. D.; SOARES, F. A. A. Uso de seminários na disciplina de Química como estratégia para promoção da saúde. Experiências em Ensino de Ciências, v. 11, n. 1., p. 126137, 2016.

MELLO, E. A.; ABREU, F. F.; ARAÚJO, M. I. O. A nutrição e alimentação saudável em aulas de Ciências: percepções de alunos do $8^{\circ}$ ano do Ensino Fundamental. Scientia Plena, v. 9, n. 5, p. 1-9, 2013.

MORTIMER, E. F. Construtivismo, mudança conceitual e ensino de ciências: para onde vamos? Investigações em Ensino de Ciências. v. 1, n. 1, p.20-39, 1996.

OZTAS, F.; OZTAS, H. Pupils' Understanding of Food Concept: The Assessment of Children's Preconceptions Ideas about Food. Journal of Education and Practice, v. 8, n. 7, p. 145-148, 2017.

PEDRAZA, D. F.; SILVA, F. A; MELO, N. L. S.; ARAUJO, E. M. V.; SOUSA, C. P. C. Estado nutricional e hábitos alimentares de escolares de Campina Grande, Paraíba, Brasil. Ciência e Saúde Coletiva, v. 22, n. 2, p. 469-477, 2017.

PEREIRA, T. S.; PEREIRA, R. C.; PEREIRA, M. C. A. Influências de intervenções educativas no conhecimento sobre alimentação e nutrição de adolescentes de uma escola pública. Ciência e Saúde Coletiva, v. 22, n. 2, p. 427-435, 2017.

POULAIN, J. P.; PROENÇA, R. P. C. O espaço social alimentar: um instrumento para o estudo dos modelos alimentares. Revista de Nutrição, v. 16, n. 3, p. 245-256, 2003.

RIGUI, M. M. T.; FOLMER, V. SOARES, F. A.A. Concepções de estudantes do ensino fundamental de escolas públicas sobre alimentação. Vidya, v. 31, n. 1, p. 63-76, 2011.

RIGUI, M. M T.; FORGIARINI, A. M. C.; CORREA, T. M. Q. S.; FOLMER, V.; SOARES, F. A. A. Concepções de estudantes do ensino fundamental sobre alimentação e digestão. Ciência e Ideias, v. 4, n. 1, p. 1-17, 2012.

ROCHA, A. S.; FACINA, V. B. Professores da rede municipal de ensino e o conhecimento sobre o papel da escola na formação dos hábitos alimentares dos escolares. Ciência \& Educação, v. 23, n. 3, p. 691-706, 2017.

RODRIGUES, L.; CAMARGO, I.; BARIM, E. M.; DIAS, L. C. G. D. Construindo conceitos sobre alimentação saudável com escolares da rede municipal de ensino. Simbio-Logias, v. 4, n. 6, p. 144-154, 2011.

SICHIERI, R. Consumo alimentar no Brasil e o desafio da alimentação saudável.

ComCiência. n. 145. p. 1-4, 2013.

SILVA, D. C. A.; FRAZÃO, I. S.; OSÓRIO, M. M.; VASCONCELOS, M. G. L. Percepção de adolescentes sobre a prática de alimentação saudável. Ciência e Saúde Coletiva, v. 20, n. 11, p. 3299-3308, 2015a.

SILVA, E. C. R.; FONSECA, A. B. C.; DYSARZ, F. P.; REIS, E. J. Hortas escolares: possibilidades de anunciar e denunciar invisibilidades nas práticas educativas sobre alimentação e saúde. Alexandria Revista de Educação em Ciência e Tecnologia, v. 8, n. 1, p. 265-288, 2015b. 
SODRÉ, F. C. R.; MATTOS, C. R. de. Complexificando o conhecimento cotidiano: incluindo a Física na problematização da alimentação. Alexandria Revista de Educação em Ciência e Tecnologia, v. 6, n. 2, p. 53-79, 2013.

SUSANA, R. A.; LONGHI, A. L. La noción de alimentación y su representación en alumnos escolarizados. Revista Electrónica de Enseñanza de las Ciências, v. 5, n. 3, p. 534-552, 2006.

TAMAYO, A. P; NINO, L. V. M.; JUANEZ, J. C. Analysis and intervention of student knowledge of nutrition and sexuality at a penal institution. Journal of Baltic Science Education, v. 14, n. 4, p. 513-523, 2015.

TEIXEIRA, F. M.; SOBRAL, A. C. M. B. Como novos conhecimentos podem ser construídos a partir dos conhecimentos prévios: um estudo de caso. Ciência \& Educação, v. 16, n. 3, p. 667-677, 2010.

TORAL, N.; CONTI, M. A.; SLATER, C. A alimentação saudável na ótica dos adolescentes: percepções e barreiras à sua implementação e características esperadas em materiais educativos. Cadernos de Saúde Pública, v. 25, n. 11, p. 2386- 2394, 2009.

VIANA, V. Psicologia, saúde e nutrição. Análise Psicológica, n. 4, p. 611-624, 2002.

ZOMPERO, A. F.; LIMA, R. M. S. R.; LABURÚ, C. E.; FRASSON, F. A educação alimentar e nutricional nos documentos de ensino para a Educação Básica. Ciência e Ideias, v. 6, n. 2 , p. $71-82,2015$.

ZOMPERO, A. F.; FIGUEIREDO, H. R. S.; GARBIM, T. H.; Atividades de investigação e transferência de significados sobre o tema educação alimentar no ensino fundamental. Ciência \& Educação, v. 23, n. 3, p. 659-676, 2017.

\section{SOBRE OS AUTORES}

CAMILA MARIA BANDEIRA SCHEUNEMANN. Licenciada em Ciências Biológicas pela Universidade Regional do Noroeste do Estado do Rio Grande do Sul (2013). Especialista em Metodologia do Ensino de Biologia e Química pelo Centro Universitário Internacional UNINTER (2015). Especialista em Metodologia do Ensino na Educação Superior pelo Centro Universitário Internacional UNINTER (2016). Mestre em Ensino de Ciências e Matemática pela Universidade Luterana do Brasil (2018). Doutoranda em Ensino de Ciências e Matemática pela Universidade Luterana do Brasil.

PAULO TADEU CAMPOS LOPES. Licenciado em Ciências Biológicas pela Pontifícia Universidade Católica do Rio Grande do Sul. Mestre em Microbiologia Agrícola e do Ambiente e Doutor em Fitotecnia pela Universidade Federal do Rio Grande do Sul. É professor pesquisador da Universidade Luterana do Brasil (ULBRA), atuando em cursos de graduação e de pós-graduação strictu sensu. É líder do Grupo de Pesquisa Tecnologias Digitais no Ensino de Ciências, vinculado ao Programa de Pós-graduação em Ensino de Ciências e Matemática.

Recebido: 28 de fevereiro de 2018.

Revisado: 21 de julho de 2018.

Revisado: 18 de outubro de 2018.

Aceito: 21 de dezembro de 2018. 